\title{
TEXTURE AND MICROSTRUCTURE EVOLUTION DURING SUPERPLASTICITY OF THE METAL MATRIX COMPOSITE PM $2014 \mathrm{Al}-20 \% \mathrm{Al}_{2} \mathrm{O}_{3}$
}

\author{
R. KAIBYSHEV * and V. KAZYHANOV \\ Institute for Metals Superplasticity Problems RAS, \\ Khalturina 39, Ufa 450001, Russia
}

(Received in final form 28 September 1997)

The effects of superplastic deformation (SPD) on grain structure and texture evolution of the $\mathrm{Al} 2014-20 \% \mathrm{Al}_{2} \mathrm{O}_{3}$ composite produced via powder metallurgical method were investigated in conjunction with surface relief observations. Samples were deformed in tension at different strains in the range of true strain rates $10^{-4}-10^{0} \mathrm{~s}^{-1}$ at temperature $500^{\circ} \mathrm{C}$. It was found that SPD strains have a large effect on both texture and grain size. At the initial stage of superplastic flow, deformation bands are formed in the aluminum matrix along the tension direction. Simultaneously, the initial $\langle 111\rangle$ fiber texture is broken and formation of $\langle 110\rangle$ fiber texture takes place. Further strain up to $50 \%$ leads to grain structure change from banded structure to nearly equiaxed. The $\langle 111\rangle$ fiber texture is restored and texture intensity decreases with increasing strain. Strain rate dependence of texture developments showed evidence for dislocation activity in examined strain range.

The relation between microstructure evolution and texture development during superplastic deformation of the $\mathrm{PM} 2014-20 \% \mathrm{Al}_{2} \mathrm{O}_{3}$ composite is explained from the viewpoint of cooperative grain boundary sliding (CGBS).

Keywords: Metal matrix composite; Superplasticity; Texture; Grain boundary sliding

\section{INTRODUCTION}

It has been demonstrated that discontinuously reinforced metal matrix composites (MMC) can exhibit superplastic behavior at relatively high strain rates $\left(\dot{\varepsilon} \geq 10^{-2} \mathrm{~s}^{-1}\right)$ (Nieh and Wadsworth, 1991). The optimum

\footnotetext{
*Corresponding author. Fax: 7-(3472) 253-759. E-mail: rustam@metal.ugatu.ac.ru.
} 
strain rate range for superplastic deformation is from two to four orders of magnitude larger than that for monolithic aluminum alloys (Kaibyshev, 1992; Mishra et al., 1995). The SPD phenomenology of numerous MMCs has been well investigated (Nieh and Wadsworth, 1997). However, the understanding of the superplastic behavior and deformation mechanism in composite materials is still far from satisfactory compared with conventional superplastic alloys. At the same time, another unknown aspect of high strain rate superplasticity (HSRS) in MMCs is texture evolution. It is known (Padmanabhan and Lucke, 1986), that a study of the texture changes accompanying superplastic flow could elucidate the operating deformation mechanism. Perhaps the absence of these data is the reason why the origin of HSRS in MMCs is not yet clear. At the same time, a complete study of structure evolution is required to predict service properties of MMCs subjected to superplastic deformation.

The aim of this paper is to report experimental results concerning microstructural and texture changes of the composite PM 2014$20 \% \mathrm{Al}_{2} \mathrm{O}_{3}$ during superplastic deformation and to discuss the operative deformation mechanism in the light of the concept of CGBS (Astanin et al., 1994; Zelin et al., 1994).

\section{EXPERIMENTAL MATERIALS AND PROCEDURES}

The composite $\mathrm{PM} 2014-20 \% \mathrm{Al}_{2} \mathrm{O}_{3}$ was produced via a powder technology method from an aluminum alloy AA $2014(4.5 \% \mathrm{Cu}, 0.6 \%$ $\mathrm{Mg}, 0.8 \% \mathrm{Mn}, 0.8 \% \mathrm{Si}, \mathrm{Al}$ is the (balance) and $20 \% \mathrm{Al}_{2} \mathrm{O}_{3}$ particles). For structure and texture analysis the tensile samples with the gauge section of $10 \times 5 \times 2 \mathrm{~mm}$ were machined from an extruded bar, $(\varnothing 16 \mathrm{~mm})$ in the longitudinal direction with respect to the original extrusion direction. For surface examination the samples were prepolished by a diamond paste $(0.5 \mu \mathrm{m})$, final polishing was performed using a $20 \%$ nitric acid solution in methanol at $-30^{\circ} \mathrm{C}$ and $15 \mathrm{~V}$. Samples were deformed in tension in air at $T=500^{\circ} \mathrm{C}$ and at initial strain rates $8.3 \times 10^{-4}, 3.3 \times 10^{-2}$ and $8.3 \times 10^{-2} \mathrm{~s}^{-1}$ upto the fixed strains using a Schenck RMS-100 universal testing machine.

The metallographic analysis of the deformed specimens was performed using an optical microscope Neophot-32, a JSM-840 and 
a structural analyzer Epiquant. The complete $\left\{\begin{array}{lll}1 & 1 & 1\end{array}\right\}$ pole figures were determined by $\mathrm{X}$-ray measurements using a universal diffractometer DRON-4 and $\mathrm{Cu} \mathrm{K}_{\alpha}$ radiation.

\section{RESULTS}

\section{Deformation Behavior}

It was reported in prior works (Kaibyshev et al., 1994a,b) that PM 2014-20\% $\mathrm{Al}_{2} \mathrm{O}_{3}$ composite exhibits superplastic behavior at $T=$ $500^{\circ} \mathrm{C}$ in the range of high strain rates $10^{-2}-10^{-1} \mathrm{~s}^{-1}$. The optimum strain rate of superplasticity is $3.3 \times 10^{-2} \mathrm{~s}^{-1}$. At this strain rate the highest elongation-to-failure $(\delta=210 \%)$ and the maximum value of the coefficient of strain rate sensitivity $(m=0.4)$ was reached.

Typical stress-strain curves for the composite deformed at $500^{\circ} \mathrm{C}$ and in different strain rate regions of superplasticity are shown in Figs. 1-3. In all cases, there were three stages of plastic flow on the curves $\sigma-\varepsilon$. Sharp hardening takes place in the early stage of deformation at $\varepsilon=0.1$. Steady state flow with continuous increment in stress slower than that in stage 1 was observed in stage 2 . In stage 3 , after a stress peak the flow stress slowly decreases. An increase of strain rates leads to the extension of stage 1 (Fig. 2). The largest elongation is obtained in specimens exhibiting a significant extension of steady state flow (stage 2) (Fig. 3). Large elongation at the strain rate $3.3 \times 10^{-2} \mathrm{~s}^{-1}$ suggests that superplastic behavior should take place.

\section{Microstructure Evolution}

The as-received state of the composite has an anisotropic distribution of alumina particles (Fig. 4). Reinforced particles tend to align along the extrusion direction. In this direction their average length is $5 \mu \mathrm{m}$. In the transverse direction their shape is circular and their average size is $2.5 \mu \mathrm{m}$. The distribution of particles is not completely uniform. Clusters of reinforced elements are observed in the composite. The grains of the aluminum matrix in cross section are nearly equiaxed with an average size of about $2.5 \mu \mathrm{m}$. In contrast, slightly elongated grains with a size of $3 \mu \mathrm{m}$ are observed in longitudinal section. 

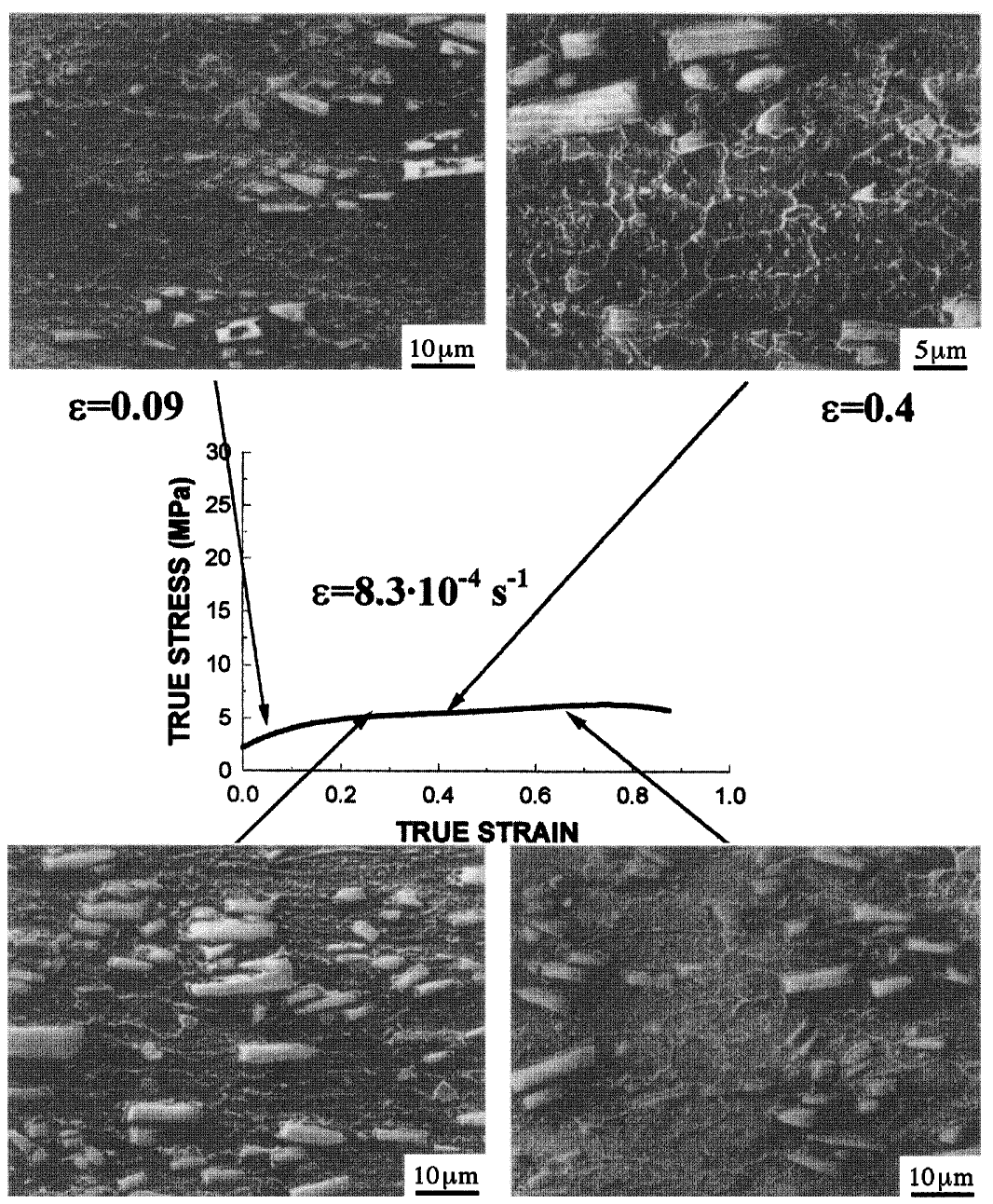

$$
\varepsilon=0.26
$$

$\varepsilon=0.4$

FIGURE 1 Micrographs showing microstructure evolution with strain during superplastic deformation at $T=500^{\circ} \mathrm{C}$ and $\dot{\varepsilon}=8.3 \times 10^{-4} \mathrm{~s}^{-1}$ of the composite PM 2014$20 \% \mathrm{Al}_{2} \mathrm{O}_{3}$ (SEM).

The effect of static heating at the temperature of deformation on grain structure change was minor. At the same time, a dynamic microstructural transition, where initial non-uniform grains transform into banded structure and after $\varepsilon=0.4$ equiaxed grains form, was found. 


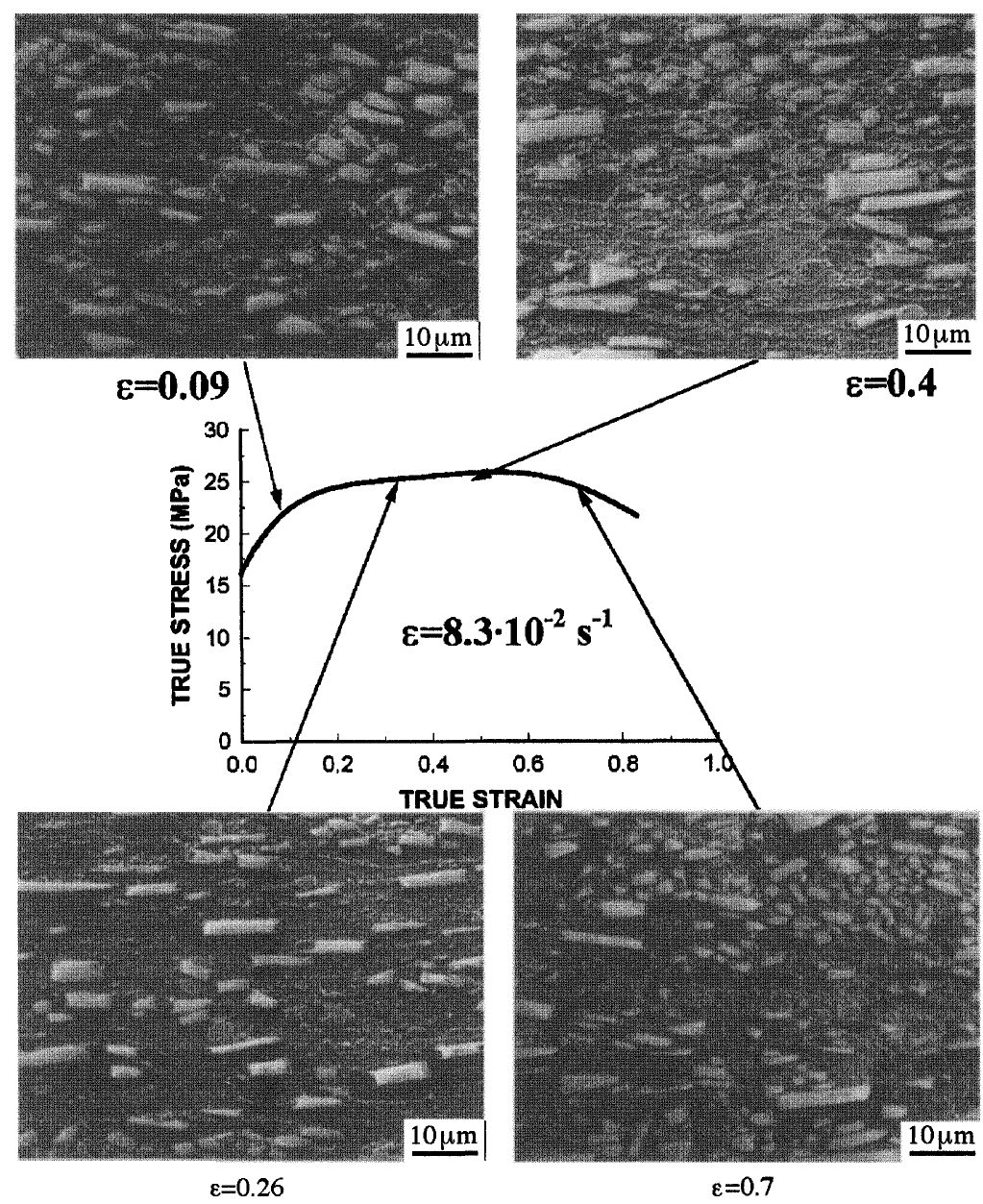

FIGURE 2 Micrographs showing microstructure evolution with strain during superplastic deformation at $T=500^{\circ} \mathrm{C}$ and $\dot{\varepsilon}=8.3 \times 10^{-4} \mathrm{~s}^{-1}$ of the composite PM 2014$20 \% \mathrm{Al}_{2} \mathrm{O}_{3}$ (SEM).

\section{Microstructural Evolution in Region I}

At the initial strains of plastic flow (stage 1), grain coarsening is observed (Fig. 1). Further deformation leads to elongation of grains in tension direction. The aspect ratio between longitudinal and transverse sizes of the matrix increases up to the strain $\varepsilon=0.7$ (Table I). 


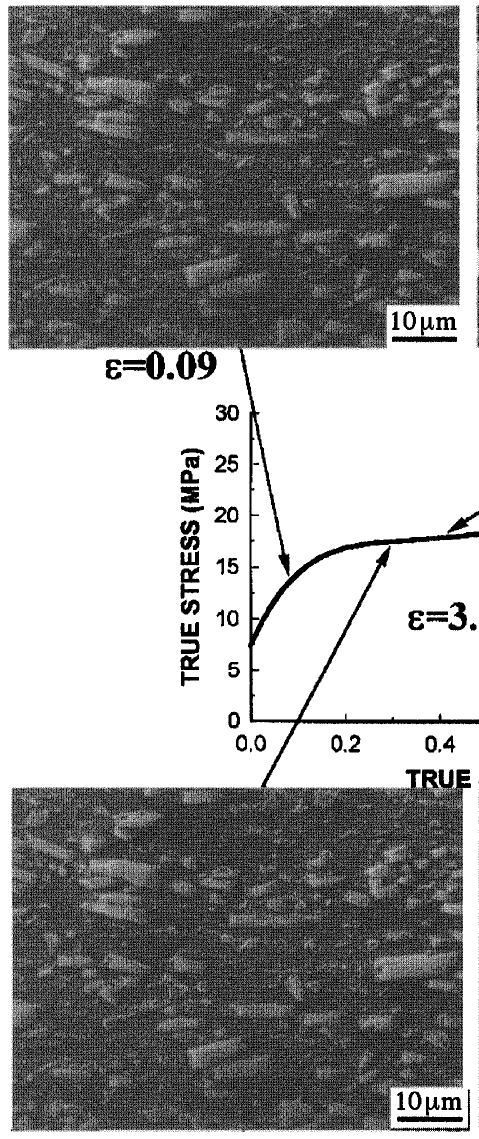

$\varepsilon=0.26$

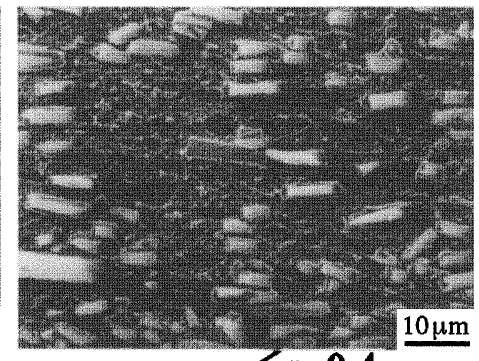

$\varepsilon=0.4$

FIGURE 3 Micrographs showing microstructure evolution with strain during superplastic deformation at $T=500^{\circ} \mathrm{C}$ and $\dot{\varepsilon}=3.3 \times 10^{-4} \mathrm{~s}^{-1}$ of the composite PM 2014$20 \% \mathrm{Al}_{2} \mathrm{O}_{3}(\mathrm{SEM})$.

TABLE I The influence of strain and strain rate on the matrix grain size $(\mu \mathrm{m})$. Notice that, the nominator is the size in longitudinal direction and the denominator is one in transverse direction

\begin{tabular}{lccc}
\hline Strain, $\varepsilon$ & \multicolumn{3}{c}{ Strain rate, $\dot{\varepsilon}\left(\mathrm{s}^{-1}\right)$} \\
\cline { 2 - 4 } & $8.3 \times 10^{-4}$ & $3.3 \times 10^{-2}$ & $8.3 \times 10^{-2}$ \\
\hline 0.4 & $5.0 / 4.2$ & $4.5 / 3.4$ & $3.3 / 2.5$ \\
0.7 & $8.5 / 5.1$ & $5.4 / 3.7$ & $4.1 / 3.5$ \\
\hline
\end{tabular}



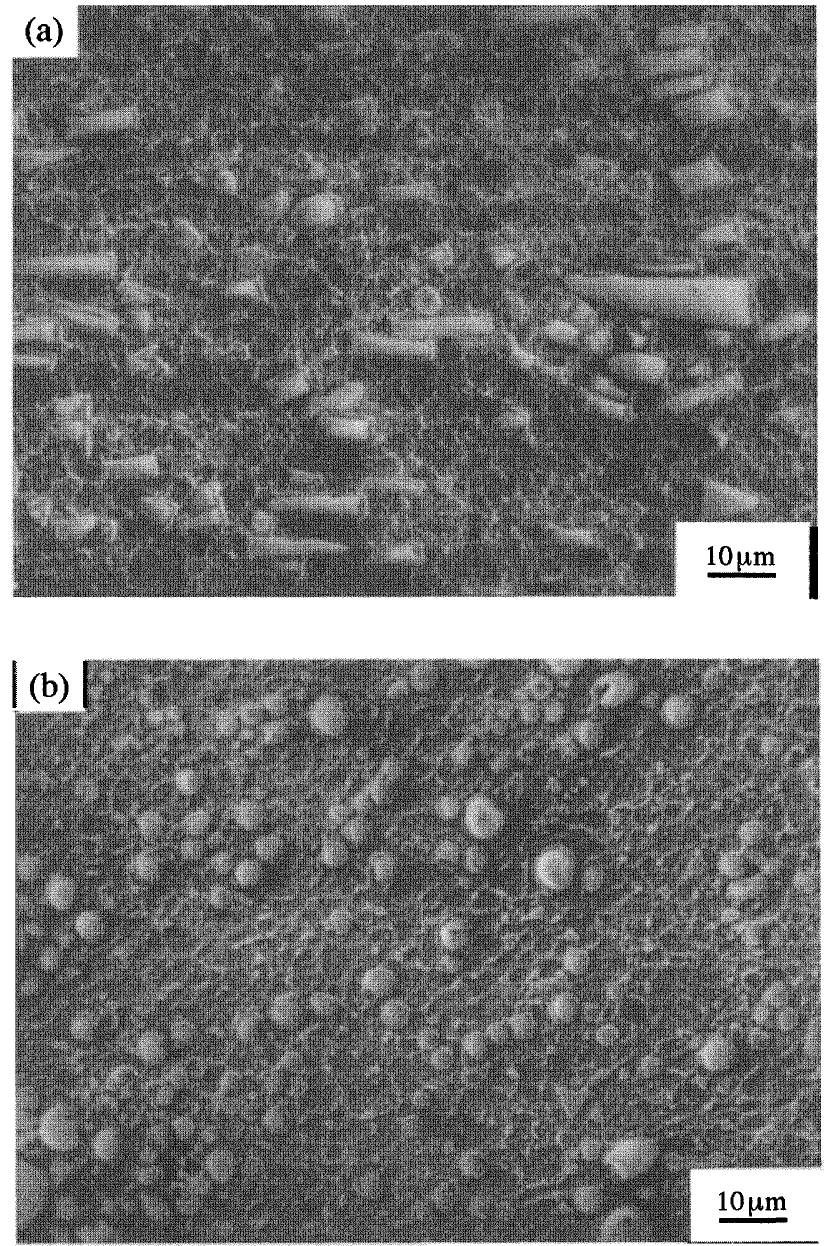

FIGURE 4 Micrograph of the as-received state of the composite PM 2014$20 \% \mathrm{Al}_{2} \mathrm{O}_{3}$ : (a) longitudinal direction and (b) cross section (SEM).

\section{Microstructural Evolution in Region II}

In region II, the small strain $(\varepsilon=0.15)$ yields formation of banded grain structure located along tension direction (Fig. 3). The length of deformation bands attains tens of microns and their width is determined by the distribution of particles in the specimen and 
constitutes about $2-8 \mu \mathrm{m}$. The broadening of deformation bands and their volume fraction increases as the strain increases up to $\varepsilon=0.25$. After this strain two structural components can be distinguished in the composite microstructure. The first component is a banded structure. This structural component occupies approximately $60 \%$ of the material volume and locates in the particle-free areas. The second component is comprised of circular grains of about $5 \mu \mathrm{m}$ in size. This structure is observed in areas of reinforced element clusters. At further deformation a dynamic recrystallization occurs in the banded structure. As a result, an uniform granular structure forms in the whole volume of the composite at $\varepsilon=0.4$. This strain corresponds to the onset of stage 2 of the curves $\sigma-\varepsilon$. Following deformation up to the strain $\varepsilon=0.7$ causes continuous equiaxialization and growth of matrix grains.

\section{Microstructural Evolution in Region III}

Plastic deformation in region III leads to a slight grain growth in the aluminum matrix and elongation of these grains toward the tension direction. Band formation occurred up to $\varepsilon=0.4$. A refinement of initial grains occurs at strain rates higher than $\dot{\varepsilon}=10^{-1} \mathrm{~s}^{-1}$.

\section{Texture Changes During Deformation}

In the as-received state of the composite a rather weak $\langle 111\rangle$ fiber texture was observed (Fig. 5(a)). Isochronal annealing at $T=500^{\circ} \mathrm{C}$ negligibly influences texture intensity. In contrast, superplastic deformation leads to systematic texture evolution with the strain. Deformation up to strain $\varepsilon=0.2$ results in a break and randomization of the initial texture (Figs. 5(b) and (d)). Strain increase up to $\varepsilon=0.4$ results in restoration of the $\langle 111\rangle$ fiber texture. Further deformation up to the strain $\varepsilon=0.7$ does not significantly affect intensity and type of the texture (Figs. 5(c) and (e)).

Inspection strain rate dependence of texture formation shows that in region II the overall texture decreases during following superplastic deformation (Fig. 5(f)). The texture was rather random and close to the $\langle 110\rangle$ fiber texture at strain up to $\varepsilon=0.25$ (Figs. 5(f) and (g)). Following deformation leads to formation and gradual weakening of the initial texture (Fig. 5(h)). 
a

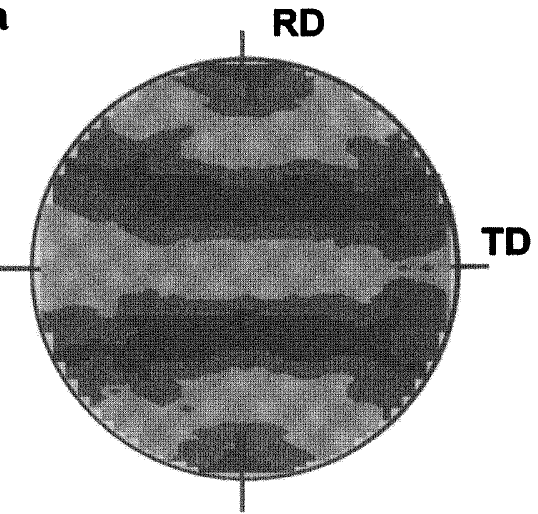

b

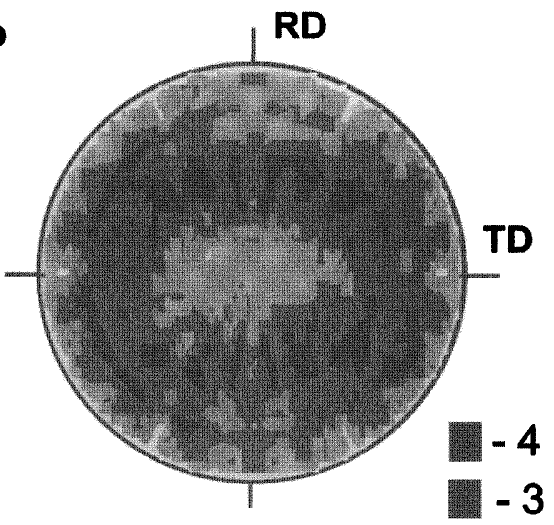

c

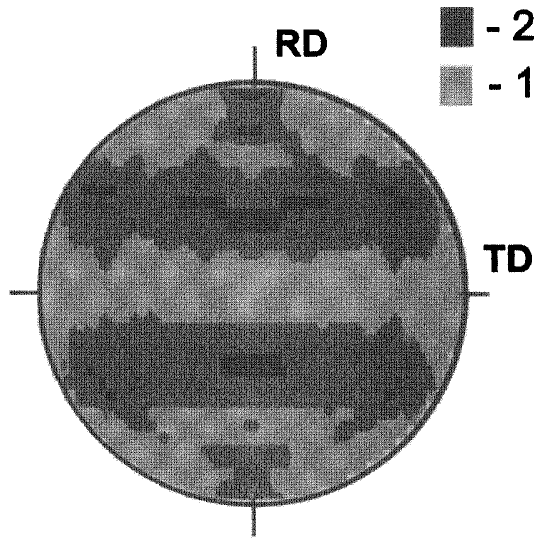

FIGURES 5(a)-(c) 

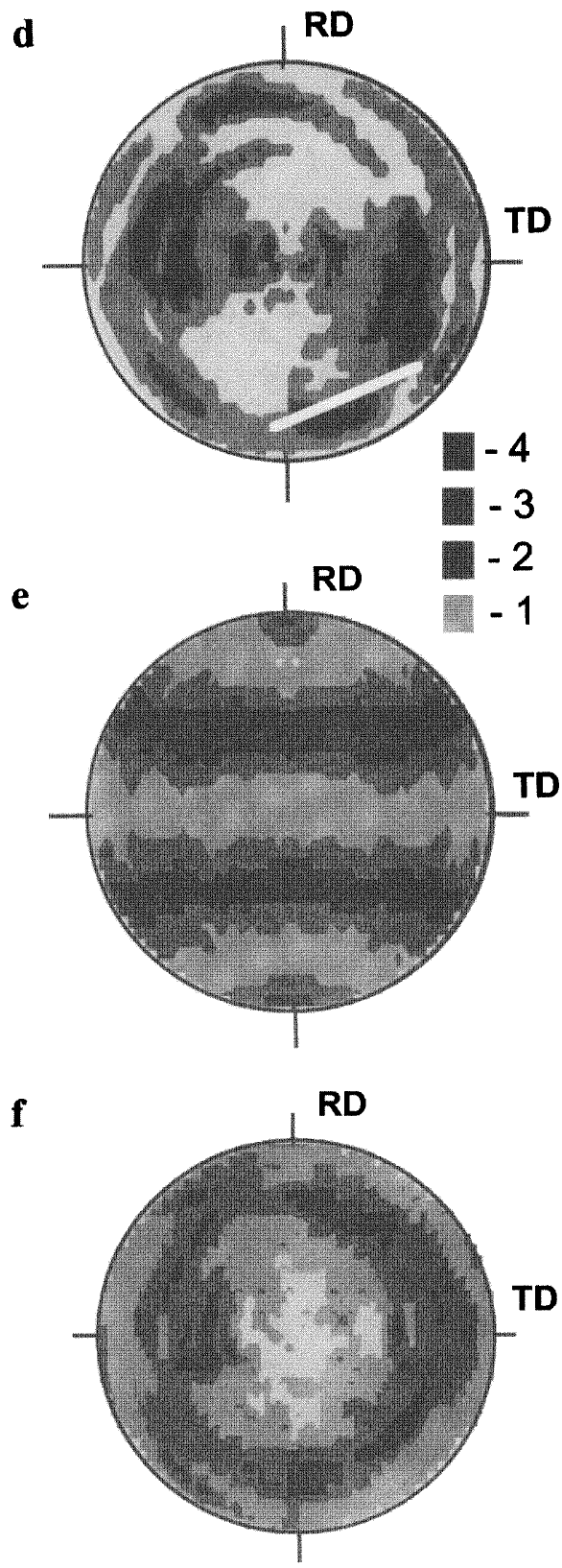

FIGURES 5(d)-(f) 


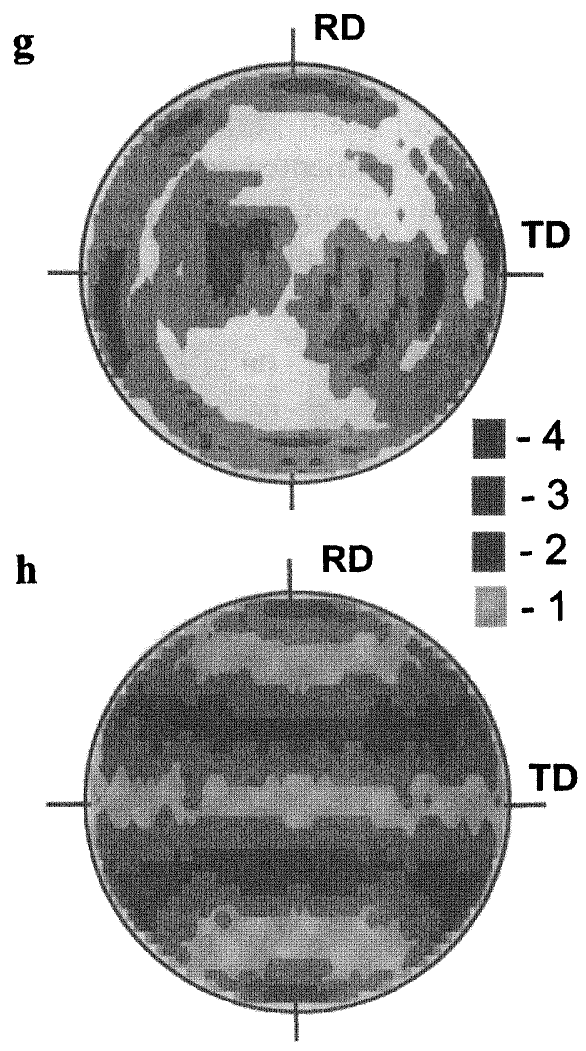

FIGURES 5(g) and (h)

FIGURE $5\langle 111\rangle$ pole figures for the composite $\mathrm{PM} 2014-20 \% \mathrm{Al}_{2} \mathrm{O}_{3}$ : (a) the as-received state; after deformation at $T=500^{\circ} \mathrm{C}, \dot{\varepsilon}=8.3 \times 10^{-4} \mathrm{~s}^{-1}$; (b) $\varepsilon=0.18$; (c) $\varepsilon=0.7, \dot{\varepsilon}=8.3 \times 10^{-2} \mathrm{~s}^{-1}$; (d) $\varepsilon=0.3$; (e) $\varepsilon=0.7, \dot{\varepsilon}=3.3 \times 10^{-2} \mathrm{~s}^{-1}$; (f) $\varepsilon=0.18$; (g) $\varepsilon=0.26$; (h) $\varepsilon=0.4$; (h) $\varepsilon=0.7$.

\section{Surface Microstructural Observations}

At all examined strain rates the grain groups slide as an entity (Astanin et al., 1994; Zelin and Mukerjee, 1995; Zelin et al., 1994). Evidence of CGBS was revealed at all studied deformation conditions. At the same time, the surface metallographic features depended on strain rates. The character of matrix grains, sliding in groups, and the size of the grain groups are different in the three strain rate ranges. 
In region I two systems of CGBS are operative in the early stage of plastic flow (Fig. 6(a)). It is difficult to reveal a preliminary CGBS system. The shift of grain groups occurs along two systems of grain boundary surfaces oriented at an angle of $\sim 60^{\circ}$ to the tensile axis. As a result, the grain groups are equiaxed. The surfaces of the grain boundaries are not planer. Surface bending is observed
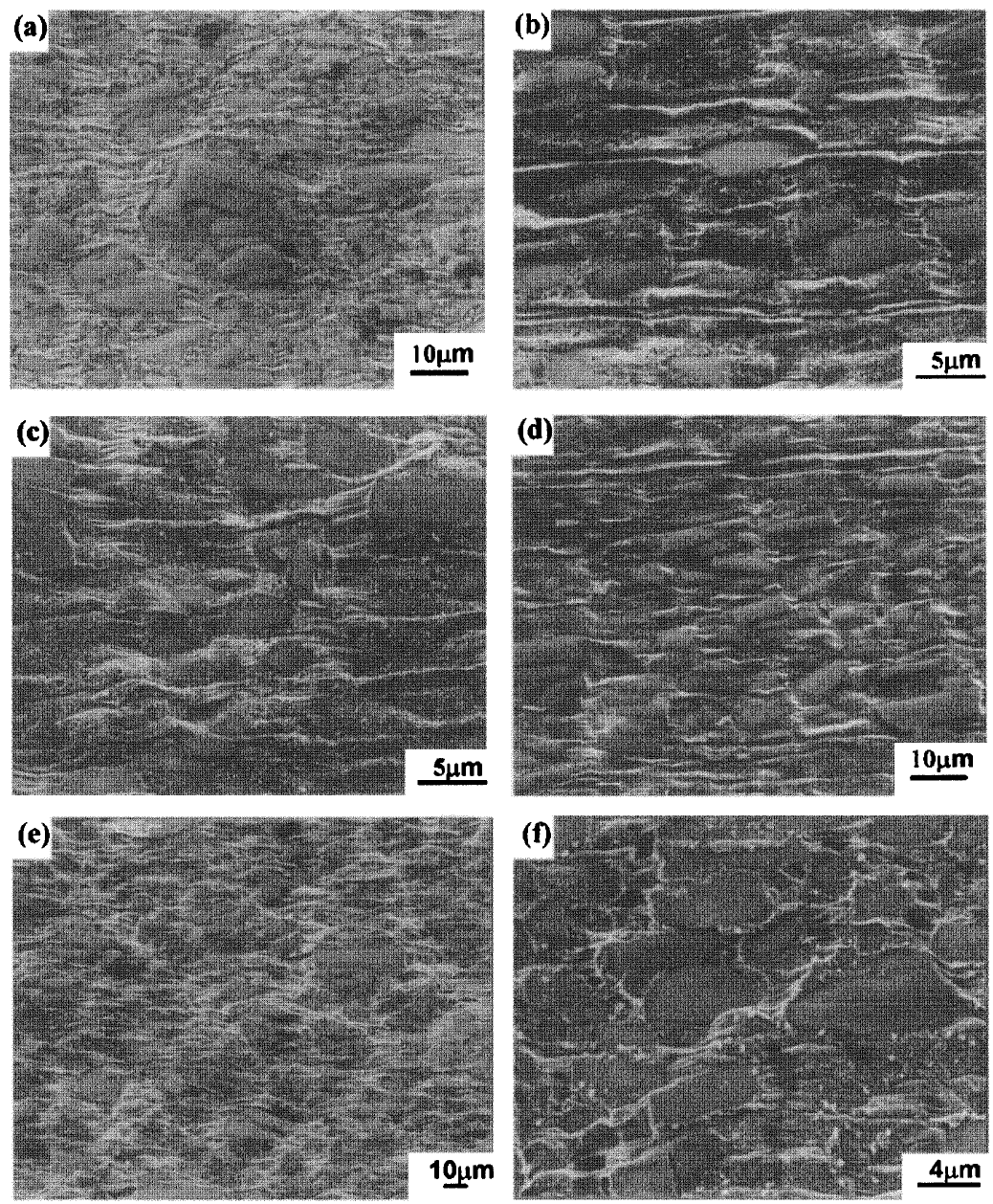

FIGURE 6 Deformation relief at $T=500^{\circ} \mathrm{C}$ : (a) $\dot{\varepsilon}=8.3 \times 10^{-4} \mathrm{~s}^{-1}, \varepsilon=0.14$; (b) $\dot{\varepsilon}=$ $1.6 \times 10^{-2} \mathrm{~s}^{-1}, \varepsilon=0.14$; (c) $\varepsilon=0.33$; (d) and (e) $\varepsilon=0.6$; (f) $\dot{\varepsilon}=1.6 \times 10^{-1} \mathrm{~s}^{-1}, \varepsilon=0.18$. Note that the tensile axis is horizontal (SEM). 
in the sites of intersection of the surfaces and reinforced particles. The sliding grain groups shift as a unit along common grain boundary surfaces. They are located in the areas of reinforcement clusters. Their size is about 2-4 in units of an average matrix grain size. Strain increase leads to reduction of the grain group size up to 2. The same tendency was found in monolithic alloys (Zelin and Mukerjee, 1995; Zelin et al., 1994).

In region II only one system of CGBS is observed at a small strain (Fig. 6(b)). The stringers of deformation bands of this system are continuous and oriented at an angle of $\sim 70^{\circ}$ to the tensile axis. Their length is about $20-50 \mu \mathrm{m}$. The spacing between these bands is about 3-4 in units of average matrix grain size. The grain groups have a right-angular shape. In general, the shift of longitudinal scratches is observed. However, it is seen from Fig. 6(b) that there are no shifts of some scratches on grain boundaries although the strain is basically accumulated due to CGBS. It was shown by Zelin et al. (1994) that not only the scratch shift but also the breakage of these scratches indicates the contribution of GBS to the total deformation.

Notice that formation of continuous CGBS surfaces occurs as a result of sliding along intergranular boundaries. Interfacial sliding was not observed. Evidence of CGBS is observed in the vicinity of the particles only in the case when the $\mathrm{Al}_{2} \mathrm{O}_{3}$ is located on an $\mathrm{Al} / \mathrm{Al}$ boundary. An increase in strain up to $\varepsilon=0.33$ leads to a decrease in spacing of about 3 (Fig. 6(c)). In macroscale the bands form stringers, which traverse the specimens from one edge to the other. Notice that the stringers are rather discontinuous. In addition, in some areas of the tested sample, evidence of a secondary CGBS system is detected. However, its amount is insignificant in comparison with traces of the primary CGBS system.

Further strain up to $\varepsilon=0.6$ leads to a strong reduction of the spacing up to 1-2 and a significant increase in broadening of deformation bands (Fig. 6(d)). The primary system of CGBS is dominant. Evidence of the operation of a secondary CGBS system was rarely observed. As usual, GBS occurs along common surfaces consisting of grain boundaries of different grain groups. These surfaces are not flat and there is surface irregularity in the sites of transition from one grain group to another. 
In region III GBS is also operative (Fig. 6(f)). However, the degree of cooperation of GBS is much less. It is rather difficult to recognize the stringers of CGBS. One system of CGBS prevails. The spacing between these stringers is $1-2$ in units of average grain size. In general, GBS of individual matrix grains takes place. The mutual sliding and rotation of grains along stringers of CGBS are well revealed while sliding along individual intergranular grain boundaries can be detected only by the scratch shift. The intensity of GBS at high strain rates is less than at low strain rates. This is caused by the fact that the contribution of dislocation glide to the total deformation is dominant (Kaibyshev, 1992). This is evident from the reduction in spacing between parallel longitudinal scratches. Consequently, the contribution of GBS to the total elongation is not high.

\section{DISCUSSION}

\section{Operating Deformation Mechanisms}

It was shown in prior works (Kaibyshev et al., 1994a,b) that the deformation of the $\mathrm{PM} 2014-20 \% \mathrm{Al}_{2} \mathrm{O}_{3}$ composite is controlled by deformation in the aluminum matrix. The difference between the deformation behaviors of the composite and its monolithic alloy is associated with the influence of reinforced elements on the deformation mechanisms in the aluminum matrix. It is generally known (Kaibyshev, 1992) that in monolithic alloys GBS is the dominant deformation mechanism in region II. However, the contribution of GBS to the total elongation decreases in regions I and III. The conducted experiments show that in the case of the composite, the situation is the same. The occurrence of extensive GBS is evident from direct surface microstructural examination and consistent with an experimental value of $m=0.4$ in region II.

At the same time, the character of CGBS is not typical for conventional superplasticity (Astanin et al., 1994; Zelin and Mukerjee, 1995; Zelin et al., 1994). At the optimum strain rate of superplastic deformation the secondary system of CGBS begins to act only after large strain. In addition, the size of grain groups is significantly less than in monolithic aluminum alloys (Novikov et al., 1991). Probably, the latter 
causes a shift of region II toward higher strain rates in the composite as compared to the monolithic alloys.

\section{Deformation Mechanisms and Structural Evolution}

It is known (Kaibyshev, 1992; Kaibyshev et al., 1994b), that dynamic changes in grain size and texture evolution are caused by the operation of different modes of deformation during superplastic flow. Accordingly, unusual structure and texture evolution, observed in the composite during superplastic deformation can be explained in terms of the dominant deformation mechanisms.

In region I multiple CGBS and single dislocation glide are the main deformation mechanisms. As a result, the $\langle 111\rangle$ initial fiber texture is preserved during deformation and its randomization is observed. Lattice dislocations are trapped by matrix grain boundaries during plastic deformation. Sliding along grain boundary surfaces results in adsorption of trapped dislocations by matrix grain boundaries. This leads to an increase of grain boundary energy and provides extensive grain growth due to deformation induced grain boundary migration coupling with CGBS. At the same time, GBS does not occur along boundaries in the grain group interior. Dislocation sliding in these "internal" grains yields their elongation toward the tension direction. In addition, accumulation of lattice dislocations inside these grains and into their boundaries takes place in the initial stage of plastic flow. As strain increases the average size of the grain groups drops. GBS becomes more uniform and occurs along most of the matrix boundaries. As a result, a reduction in lattice dislocation density takes place (Kaibyshev et al., 1994a).

In region II single CGBS leads to a great shift of the grain groups in the aluminum matrix. Most likely, this shift is accommodated by single slip. Operation of these two deformation mechanisms yields microstructural band appearing in the reinforced particle-free areas. The details of the formation of these bands are not yet clear. However, it is possible to presume that this process occurs due to the coalescence of matrix grains inside of the grain groups and deformation induced migration of transverse boundaries of the grain groups. It is known (Zelin et al., 1994), that an extensive grain growth takes place in bands of CGBS in monolithic alloys. In any case, band formation leads to 
disappearance of the initial texture and formation of the nonsymmetric one after $\varepsilon=0.1$. Dislocation density sharply increases in coarse deformation bands (Kaibyshev et al., 1994a). Dislocation accumulation inside the bands provides critical conditions for the occurrence of dynamic recrystallization. This leads to the formation of fine equiaxed grains. CGBS takes place along their boundaries. As a result, after large strain, the CGBS becomes more uniform. Mutual sliding of matrix grains provides the best conditions for the adsorption of trapped lattice dislocations into grain boundaries. This yields a significant reduction of lattice dislocation density (Kaibyshev et al., 1994a).

In region III the dominant multiple slip provides the stabilization of the initial $\left\langle\begin{array}{lll}1 & 1 & 1\end{array}\right\rangle$ fiber texture and results in elongation of matrix grains in the tension direction. Slight weakening of texture intensity is caused by GBS which is operative at a level of individual grains. The velocity of adsorption of grain boundary dislocations due to GBS is less than that of lattice dislocation generation. As a result, plastic deformation leads to an increase in dislocation density (Kaibyshev et al., 1994a).

\section{References}

Astanin, V.V., Kaibyshev, O.A. and Faizova, S.N. (1994). The role of deformation localization in superplastic flow. Acta Metallurgica et Materialia, 42, 2617-2622.

Kaibyshev, O.A. (1992). Superplasticity of Alloys, Intermetallides, and Ceramics, p. 316. Berlin: Springer-Verlag.

Kaibyshev, R., Kazykhanov, V., Evangelista, E. and Stobrawa, J. (1994a). Superplasticity of the metal matrix composite PM $2014 \mathrm{Al}-20 \% \mathrm{Al}_{2} \mathrm{O}_{3}$. Materials Science Forum, 170-172, 525-530.

Kaibyshev, R., Kazykhanov, V., Astanin, V. and Evangelista, E. (1994b). The influence of reinforced elements on deformation behavior of the aluminum alloy. Materials Science Forum, 170-172, 531-536.

Mishra, R.S., Bieler, T.R. and Mukherjee, A.K. (1995). Superplasticity in powder metallurgy aluminum alloys and composites. Acta Metallurgica et Materialia, 43, 877-891.

Nieh, T.G. and Wadsworth, J. (1991). High-strain-rate superplasticity in aluminium matrix composites. Materials Science and Engineering, A147, 129-142.

Nieh, T.G. and Wadsworth, J. (1997). Superplasticity at high strain rates in metals and their composites. Materials Science Forum, 243-245, 257-266.

Novikov, I.I., Portnoy, V.K., Iljenko, V.M. and Levchenko, V.S. (1991). Structural peculiarities of aluminium alloy after superplastic deformation at anomalous high strain rate. Superplasticity in Advance Materials. edited by S. Hori, M. Tokizane and N. Furushiro, pp. 121-125. Japan Society for Research on Superplasticity. 
Padmanabhan, A. and Lucke, K. (1986). An assessment of the role of texture in superplastic flow. Z. Metallkunde, 77, 765-769.

Zelin, M.G. and Mukherjee, A.K. (1995). Cooperative phenomena at grain boundaries during superplastic flow. Acta Metallurgica et Materialia, 43, 2359-2372.

Zelin, M.G., Krasilnikov, N.A., Valiev, R.Z., Grabski, M.W., Yang, H.S. and Mukherjee, A.K. (1994). On the microstructural aspects of the nonhomogeneity of superplastic deformation at level of grain groups. Acta Metallurgica et Materiala, 42, 119-126. 